\title{
Temporal and spatial control of the mother-cell regulatory gene spoIIID of Bacillus subtilis
}

\author{
Barbara Kunkel, ${ }^{1}$ Lee Kroos, ${ }^{1,3}$ Harold Poth, ${ }^{2,4}$ Philip Youngman, ${ }^{2}$ and Richard Losick ${ }^{1,5}$ \\ ${ }^{1}$ Department of Cellular and Developmental Biology, The Biological Laboratories, Harvard University, Cambridge, \\ Massachusetts 02138 USA; ${ }^{2}$ Department of Microbiology, University of Pennsylvania School of Medicine, Philadelphia, \\ Pennsylvania 19104 USA
}

Gene expression during endospore formation in Bacillus subtilis is compartmentalized between the mother-cell and forespore chambers of the sporangium, which follow separate pathways of cellular differentiation. The earliest acting regulatory gene so far identified in the mother-cell line of gene expression is spoIIID, whose product is required for the transcription of the composite gene (sigK) encoding the mother-cell RNA polymerase $\sigma$-factor $\sigma^{\mathrm{K}}$ and for the chromosomal rearrangement that gives rise to the composite gene. Here we report the nucleotide sequence of spoIIID and studies on the temporal, spatial, and genetic control of its expression during sporulation. We show that the deduced spoIIID gene product, a 93-residue-long polypeptide, is a previously identified transcription factor that is known to activate the promoter for the sigK gene in vitro. Expression of spoIII is largely confined to the mother-cell chamber of the sporangium and is turned on at, or shortly before, the time (hour 3 of sporulation) that the mother-cell chromosome is rearranged and transcription of the sigK gene commences. This gene expression depends strongly on the sporulation $\sigma$-factor $\sigma^{\mathrm{E}}$ and partially on the spoIIID gene product, itself. We conclude that the timing and compartmentalization of the rearrangement and transcription of the sigK gene and, hence, of subsequent gene activation in the mother cell, are, in part, direct consequences of the temporal and spatial control of spoIIID gene expression.

[Key Words: Bacillus subtilis; sporulation; transcription factor]

Received June 5, 1989; revised version accepted August 10, 1989.

Endospores of the gram-positive bacterium Bacillus subtilis are a dormant cell type that is produced by a process of cellular differentiation (Piggot and Coote 1976; Losick and Youngman 1984; Losick et al. 1986). The transformation of a vegetative cell into an endospore takes place within a sporangium that is composed of two compartments known as the forespore and the mother cell. The compartments each receive a chromosome from the last round of vegetative DNA replication but then follow divergent pathways of cellular differentiation. The forespore ultimately becomes the mature endospore and is the site of production of a family of small, basic proteins known as SASP (Francesconi et al. 1988; Setlow, 1988). The mother cell, on the other hand, is the site of production of the tough protein coat that encases the endospore (Aronson and Fitz-James 1976; Jenkinson et al. 1981; Donovan et al. 1987). After maturation of the endospore, the mother-cell compartment is discarded by lysis. Gene expression in the two compartments is regulated differentially (De Lencastre and Piggot 1979; Errington and

${ }^{3}$ Present address: Department of Biochemistry, Michigan State University, East Lansing, Michigan 48824 USA; ${ }^{4}$ Department of Microbiology, Gesellschaft für Biotechnologie Foschung mbH, D-3300 Braunschweig, FRG; ${ }^{5}$ Corresponding author.
Mandelstam 1986b; Turner et al. 1986), with certain genes, such as the SASP-encoding $s s p A-s s p E$ genes, being expressed from the forespore chromosome (Mason et al. 1988), and other genes, such as the spore coat protein genes $\cot A-\cot D$, being expressed from the mothercell chromosome (Sandman et al. 1988; Cutting et al. 1989; L. Zheng and R. Losick, unpubl.). This differential gene regulation is governed, in part, by compartmentspecific $\sigma$ factors known as $\sigma^{\mathrm{G}}$ and $\sigma^{\mathrm{K}}$. $\sigma^{\mathrm{G}}$ is present in the forespore, where it directs transcription of $s s p A-$ $s s p E$ and other forespore-expressed genes (KarmazynCampelli et al. 1989; Sun et al. 1989). $\sigma^{\mathrm{K}}$, on the other hand, is present in the mother cell, where it governs the expression of $\cot A, \cot D$, and $\operatorname{ger} E$, a regulatory gene whose product induces, in turn, the expression of $\cot B$ and $\cot C$ genes (Kunkel et al. 1988; Kroos et al. 1989; L. Zheng and R. Losick, unpubl.).

Here we consider mechanisms governing the mothercell line of gene expression. It was known from previous work that the structural gene $\operatorname{sig} K$ for the mother-cell $\sigma$-factor $\sigma^{\mathrm{K}}$ is created by a DNA rearrangement in the mother-cell chromosome that brings together the coding sequences of two truncated genes, spoIVCB and spoIIIC (Stragier et al. 1989). The chromosomal rearrangement is 
due to a site-specific recombinational event, which is, in turn, dependent on the product of the sporulation regulatory gene spoIIID (Stragier et al. 1989). The precise role of the spoIIID gene product in the chromosomal rearrangement is not understood. It could turn on the expression of the recombinase gene and/or participate directly in the recombination process (see Discussion). In either case, the spoIIID gene product also directly governs expression of the rearranged gene by turning on transcription from the promoter for sigK (Kunkel et al. 1988; Kroos et al. 1989|. On the other hand, the spoIIID gene product is not required for the transcription of genes whose expression is confined to the forespore $(\mathrm{Er}$ rington and Mandelstam 1986b; De Lencastre and Piggot 1979; Mason et al. 1988; Panzer et al. 1989) or genes whose expression is switched on prior to the stage at which the sporangium is partitioned into forespore and mother-cell compartments (e.g., Errington and Mandelstam 1986a). Hence, spoIIID is a compartment-specific regulatory gene, representing, as far as is known, the earliest acting regulatory gene in the mother-cell line of gene expression (Turner et al. 1986).

To investigate the role of spoIIID in compartmentspecific gene expression, we undertook the cloning of spoIIID to investigate the nature of its product and to study temporal, spatial, and genetic aspects of its regulation.

\section{Results}

\section{Cloning the spoIIID gene}

The spoIIID gene was cloned in $B$. subtilis by selection for complementation of mutation spoIIID83, using a newly devised 'prophage transformation' system based on a derivative of the $B$. subtilis temperate phage SP $\beta$ (Poth and Youngman 1988). One such recombinant phage that was capable of complementing spoIIID83 contained a $B$. subtilis chromosomal insert of $\sim 6 \mathrm{~kb}$. To subclone spoIIID sequences from phage DNA, we took advantage of the presence of a derivative of the $E$. coli plasmid vector $\mathrm{pBR} 322$ in the SP $\beta$ phage at a location adjacent to the site of the $B$. subtilis chromosomal DNA insert (Poth and Youngman 1988). As described in Methods, competent cells of $E$. coli were transformed with phage DNA that had been digested with EcoRI and then recircularized. One such transformant contained a plasmid (p $\beta E-68)$ with a $B$. subtilis chromosomal insert of $5.7 \mathrm{~kb}$ (Fig. 1). This plasmid corrected the sporulation block of spoIIID83 mutant cells when introduced by transformation.

To localize spoIIID on the cloned fragment, we tested the capacity of subcloned segments of the $5.7-\mathrm{kb}$ insert to correct the spoIIID83 mutation by transformation (Fig. 1). Subclones were generated by use of the indicated restriction sites and by use of the indicated deletion end points that had been generated by the single-stranded DNA deletion method of Dale et al. (1985; see Methods). The experiments of Figure 1 show that the wild-type allele of spoIIID lies within the $\sim 300$-bp interval between the DraI site and the deletion end point $\Delta 3$.

\section{Localization of the spoIIID open reading frame}

To localize spoIIID further, we determined the nucleotide sequence of DNA across the region found to exhibit spoIIID-transforming activity. This analysis revealed an open reading frame (ORF) of 93 codons that overlapped extensively with the DraI $-\Delta 3$ interval that contains the wild-type allele of spoIIID83 (Fig. 2). The following lines of evidence strongly suggest that the ORF is the spoIIID gene:

1. Experiments (see below) in which the lac $Z$ gene of $E$. coli was fused in-frame to the first codon of the ORF showed that the putative spoIIID ORF is used in vivo and directs $\beta$-galactosidase synthesis in cells undergoing sporulation.

2. No other ORF of $>43$ codons could be identified that overlapped with the region of the spoIIID 83 mutation. 3. Replacement of the ORF in the chromosome with an in vitro-constructed deletion mutation (spoIIIDSerm) gave rise to mutant cells whose phenotype was indistinguishable from that of spoIIID 83 mutant cells. The deletion mutation was constructed by replacing the interval between the RsaI site at codon 15 and the RsaI site at codon 37 with an erythromycin-resistance cassette of $\sim 1 \mathrm{~kb}$. The wild-type chromosomal ORF was substituted with the $\Delta e r m$-bearing ORF by transformation of competent cells with linearized plasmid containing the deletion-mutated DNA, as described in Methods. Like spoIIID83 mutant cells, cells containing the spoIIID$\Delta$ erm mutation were blocked at stage III of sporulation and were unable to support spoIVCB-directed $\beta$-galactosidase synthesis (Fig. 3).

4. A 500-bp fragment that extended from an $\mathrm{XmnI}$ site located $\sim 230$ bp upstream of the first codon of the ORF to an XmnI site located $30 \mathrm{bp}$ downstream of the end of the ORF was capable of complementing spoIIID83. The 500-bp XmnI-XmnI fragment was introduced into the $B$. subtilis chromosome by insertion into the amylase |amy| locus (Shimotsu and Henner 1986) by use of the amy insertion plasmid pDG268 (Karmazyn-Campelli et al. 1989; see Methods). Strains containing the XmnI-XmnI fragment at amy and the spoIIID 83 or the spoIIID $\Delta$ erm mutations at the spoIIID locus were found to sporulate normally.

Assuming, then, that the 93-codon ORF is the spoIIID gene, a further issue is whether the spoIIID83 and spoIIID $\Delta$ erm mutations block sporulation by preventing the synthesis of the wild-type spoIIID gene product or by exerting a polar effect on the expression of an as yet unidentified downstream spo gene. A polar effect is, however, incompatible with the observation of complementation by the $500-b p X m n I-X m n I$ fragment, given that the $X m n I-X m n I$ fragment only contains $30 \mathrm{bp}$ of DNA downstream of the spoIIID ORF. As an independent test of polarity, a plasmid lacking a $B$. subtilis replicon (and, hence, incapable of autonomous replication in $B$. subtilis), but containing a $B$. subtilis DNA insert that extended from an $A p a L I$ site located at codon 1 of spoIIID to the XmnI site located $30 \mathrm{bp}$ downstream of the $3^{\prime}$ end of the ORF, was integrated into the $B$. subtilis 


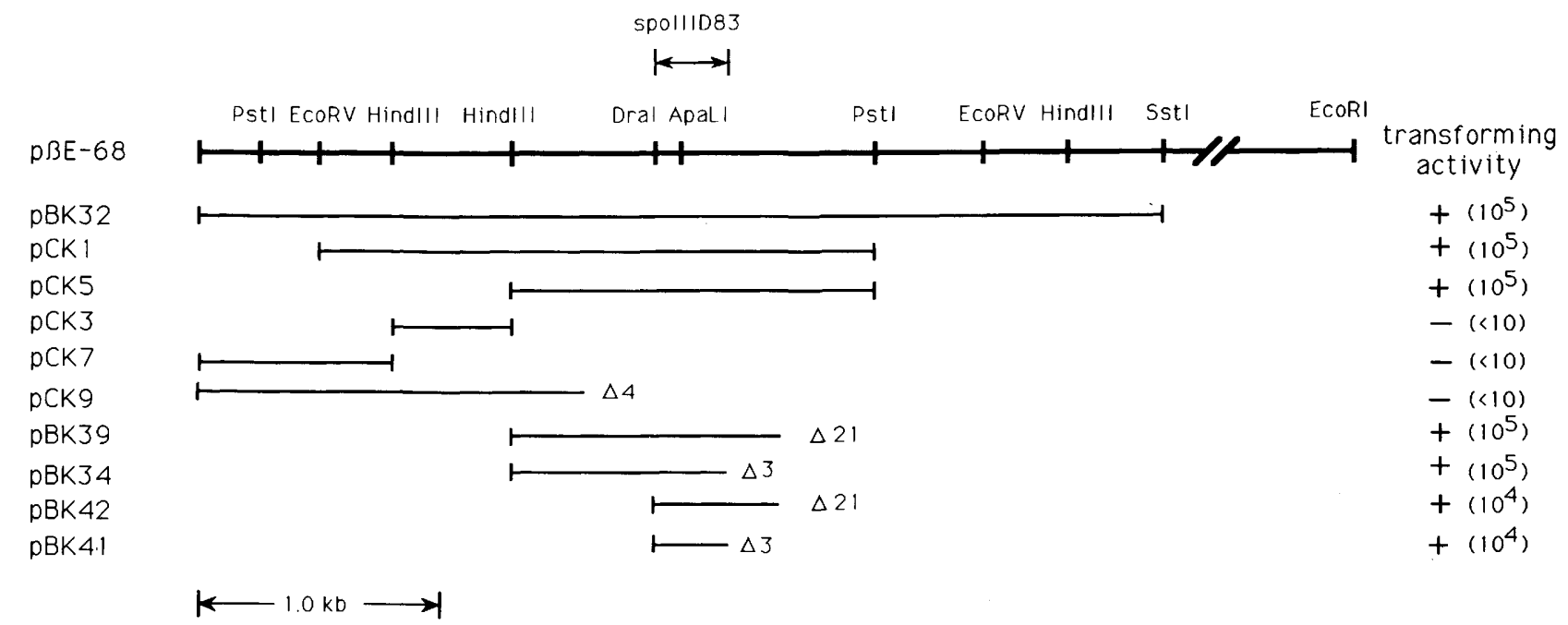

Figure 1. Physical map of the spoIIID region of the chromosome. The heavy black line represents a partial restriction site map of the $5.7-\mathrm{kb} B$. subtilis DNA insert in plasmid $\mathrm{p} \beta \mathrm{E}-68$. The left-hand boundary of the insert is the BamHI/Sau3A junction generated by cloning chromosomal DNA fragments generated by partial digestion with Sau3A into the BamHI site of the SP $\beta$ prophage vector. The EcoRI site is the right-hand border of the insert and is $\sim 1.7 \mathrm{~kb}$ downstream of the SstI site. The thin lines represent subcloned segments of the spoIIID region generated by using the indicated restriction sites and the indicated deletion end points (see Methods). The transformation activity of each subclone was determined by transforming $0.3 \mathrm{ml}$ of competent cells of strain BK395 (spoIIID83) harvested at stationary phase with $1-10 \mu \mathrm{g}$ of plasmid DNA. The transformed cells were added to $3.0 \mathrm{ml}$ of DS medium and incubated at $37^{\circ} \mathrm{C}$ on a roller drum. The transforming activity of each clone is indicated at the right and was determined by measuring the number of heat-resistant cells present per milliliter after overnight incubation. The boundaries within which the spoIIID83 mutation lies are indicated by the double-headed arrow above the restriction map.

chromosome by single-reciprocal (Campbell-like) recombination. If the spoIIID transcription unit is an operon that extends downstream of spoIIID and if the operon contains a downstream spo gene, then the ApaLI-XmnI segment would be internal to the transcription unit, and integration of the plasmid would be expected to block expression of the spo gene and cause a $\mathrm{Spo}^{-}$phenotype. If, on the other hand, the spoIIID transcription unit does not contain a downstream spo gene, then Campbell integration would not cause a block in sporulation. Because cells containing an integrated copy of plasmid bearing the ApaLI-XmnI fragment were fully sporulation proficient, we conclude that the spoIIID transcription unit does not contain a downstream spo gene and, hence, that the spoIIID gene product is required per se for spore formation.

\section{spoliID encodes a transcription factor}

Kroos et al. (1989) previously identified a sporulation transcription factor in the size range of $8-14 \mathrm{kD}$ (arbitrarily referred to as the $14-\mathrm{kD}$ protein) that alters the specificity of RNA polymerase containing the mothercell $\sigma$-factor $\sigma^{\mathrm{K}}$. The first 34 amino acids of this factor were determined by sequential Edman degradation (underlined in Fig. 2). They conform exactly to the amino acid sequence of the predicted product $(10.8 \mathrm{kD})$ of spoIIID. Therefore, we assign spoIIID as the structural gene for the transcription factor of Kroos et al. (1989). In agreement with the observation $(R$. Halberg and $L$. Kroos, unpubl.) that the transcription factor is a se- quence-specific DNA-binding protein, the spoIIID gene product contains a region (residues 23-42) of striking similarity to the $\alpha$-helix- $\beta$-turn- $\alpha$-helix DNA-binding domains of many prokaryotic regulatory proteins (Pabo and Sauer 1984).

\section{Expression of spoIIID-lacZ}

We studied the regulation of spoIIID by using an inframe fusion of spoIIID to the lacZ gene of $E$. coli. The fusion was constructed by joining lacZ in-frame to the first codon of the spoIIID ORF at the ApaLI site (see Methods). The spoIIID-lacZ fusion was introduced into the $B$. subtilis chromosome at the spoIIID locus by single-reciprocal recombination using a plasmid (pBK45) containing the fusion and adjacent $B$. subtilis chromosomal DNA extending to a HindIII site located $\sim 700 \mathrm{bp}$ upstream of the ORF. Competent cells of wild-type $B$. subtilis were transformed using $\mathrm{pBK} 45$ and selection for the plasmid-borne chloramphenicol-resistance gene. The resulting chloramphenicol-resistant transformants were $\mathrm{Spo}^{+}$, indicating that the spoIIID transcription unit had not been disrupted by the integration event and that the $5^{\prime}$ end of the spoIIID transcription unit is located within the $700 \mathrm{bp}$ upstream of the beginning of the ORF.

spoIIID-directed $\beta$-galactosidase synthesis was measured during sporulation and was found to commence 2-3 hr after the onset of sporulation, $\sim 1 \mathrm{hr}$ before the time of induction of a lacZ fusion to sporulation gene spoIVCB (Fig. 3) and $\sim 30$ min later than the time of in- 


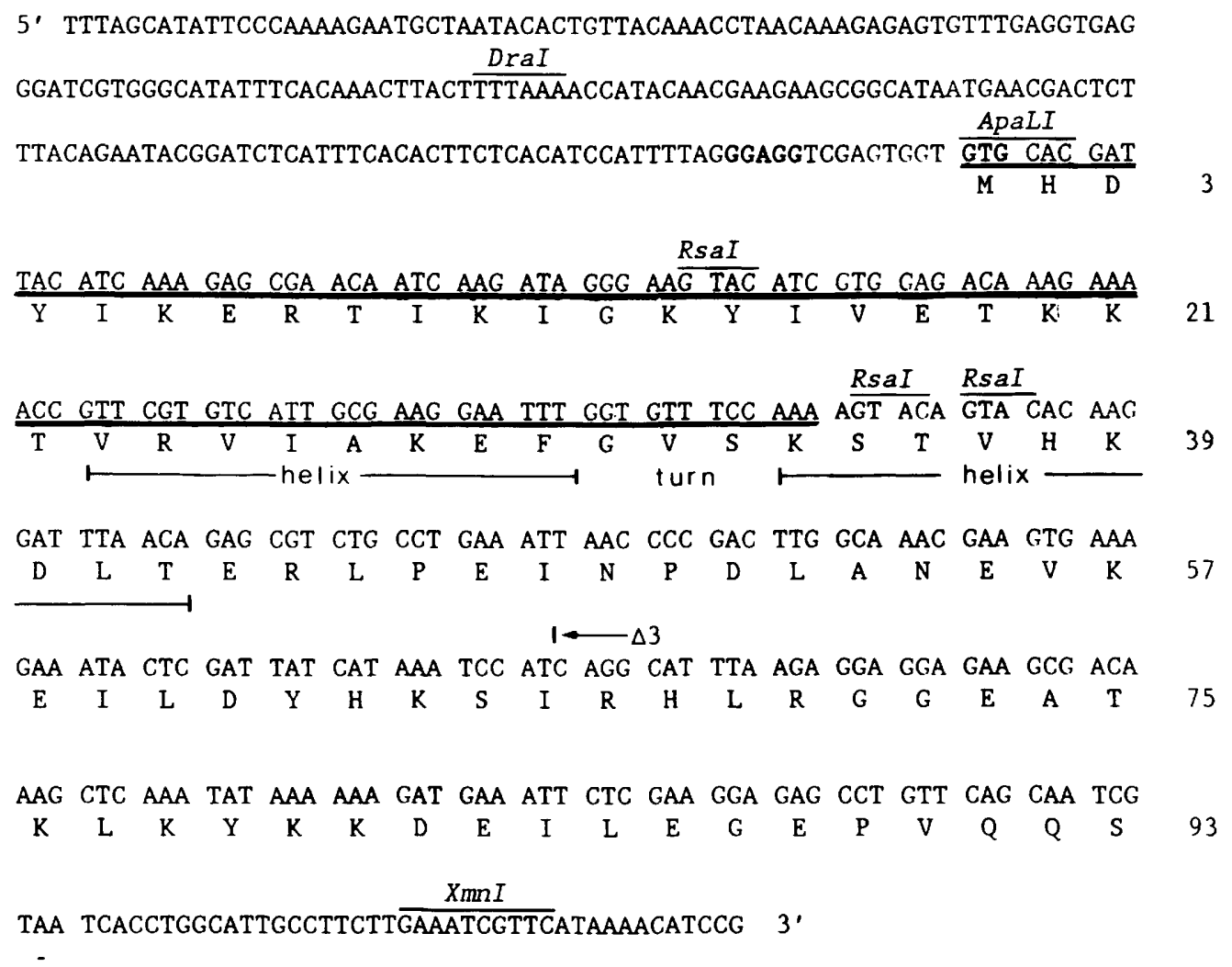

Figure 2. Nucleotide sequence of the nontranscribed strand of the spoIIID gene. The deduced amino acid sequence is shown beneath the nucleotide sequence. The putative ribosome binding site (GGAGG) is in boldface type. Numbers at right indicate positions in the amino acid sequence of the residues at the end of each line. The amino-terminal amino acid sequence of the 14-kD protein, as determined previously by sequential Edman degradation, is indicated by the thick line (residues $1-34$ ). The DraI and ApaLI restriction sites and the $\Delta 3$ deletion end point correspond to those indicated in Fig. 1. Single-letter abbreviations for the amino acid residues: (A) Ala; (C) Cys; (D) Asp; (E) Glu; (F) Phe; (G) Gly; (H) His; (I) Ile; (K) Lys; (L) Leu; (M) Met; (N) Asn; (P) Pro; (Q) Gln; (R) Arg; (S) Ser; (T) Thr; (V) Val; (W) Trp; (Y) Tyr.

duction of a lacZ fusion to the sporulation gene spoIID (data not shown).

Use of the spoIIID-lacZ fusion to study the dependence of spoIIID gene expression on other spo genes

To study the dependence of spoIIID expression on the products of other spo genes, we introduced [by transformation of competent cells with chromosomal DNA from wild-type cells bearing an integrated copy of pBK45 [see Methods)] the spoIIID-lacZ fusion into 13 spo mutants blocked at stages II-IV of sporulation. The resulting fusion-bearing strains were induced to sporulate by resuspension in SM medium and assayed for SpoIIIDdirected $\beta$-galactosidase synthesis at various times after the onset of sporulation. Time-course experiments for each mutant strain were carried out in parallel with isogenic $\mathrm{Spo}^{+}$cells bearing the spoIIID-lacZ fusion.

The levels of spoIIID-directed $\beta$-galactosidase synthesis in each of the 13 strains are listed in Table 1. Examples of the time-course experiments from which the data in Table 1 are based are presented in Figure 4. The level of expression of spoIIID-lacZ in different mutants ranged from almost complete absence of expression (spoIIAC1 and spoIIGB55) to moderate overexpression (e.g., spoIIIA53 and spoIVCB23). Several mutations, including spoIIID83, caused a partial impairment of spoIIID-lacZ expression. The two mutations that severely impaired spoIIID expression are known to prevent the appearance of the sporulation $\sigma$-factor $\sigma^{\mathrm{E}}$ (Stragier et al. 1984,1988; Labell et al. 1987; Trempy et al. 1985a,b).

\section{Compartmentalization of spolliD expression}

Because the sporangium is partitioned into mother-cell and forespore chambers by the time that spoIIID expression commences, we investigated the extent to which spoIIID expression is compartmentalized. This was determined by measuring the accumulation of spoIIIDlacZ-specified $\beta$-galactosidase in the mother-cell and forespore compartments of sporulating wild-type cells bearing the spoIIID-lacZ fusion. Fusion-bearing cells were harvested at $8-9 \mathrm{hr}$ after the onset of sporulation, and the contents of the mother-cell and forespore compartments fractionated as described previously (Kunkel et al. 1988; Cutting et al. 1989; Panzer et al. 1989). Table 


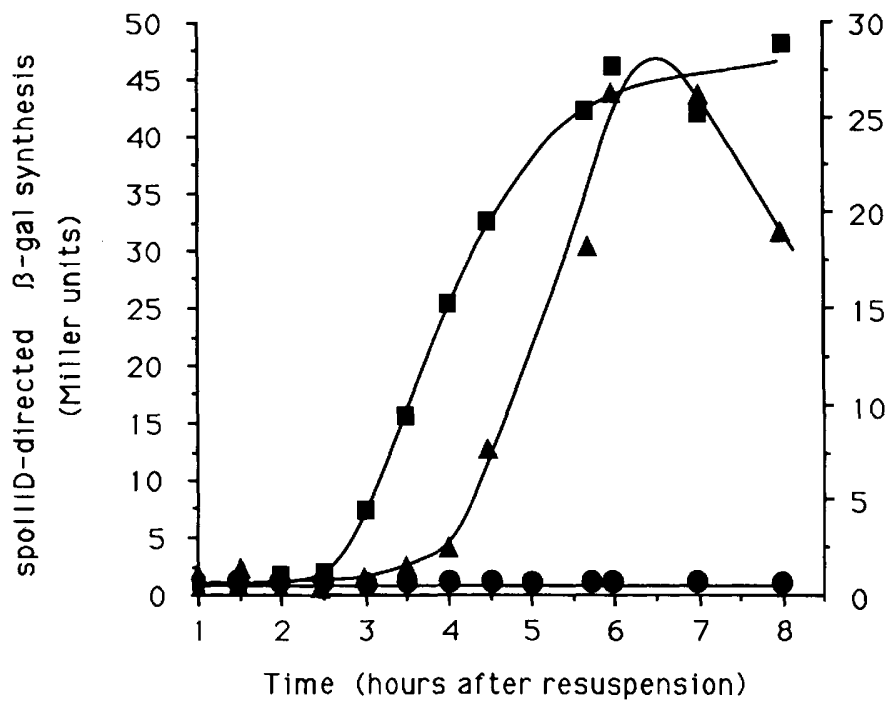

2 presents the specific activities of $\beta$-galactosidase observed in the mother-cell and forespore fractions in three independent experiments. It can be seen that the specific activity of $\beta$-galactosidase in the mother-cell fraction was about 6- to 11-fold higher (depending on the experiment) than in the forespore fraction. Thus, we conclude that $s p o I I I D$ is expressed preferentially for, more precisely, that spoIIID-lacZ-encoded $\beta$-galactosidase accumulates preferentially) in the mother cell. The extent of this compartmentalization is similar to that observed previously for other genes, such as gerE, spoIVCB, and $\cot A$ (Kunkel et al. 1988; Cutting et al. 1989; Panzer et al. 1989|, whose expression is considered to be specific to the mother cell. In contrast, $s s p B-1 a c Z$-specified $\beta$ galactosidase ( $\operatorname{ssp} B$ is a forespore-expressed gene; Mason et al. 1988) was found in a parallel experiment (see Table 2 footnote) to accumulate to 12 -fold higher specific activity in the forespore fraction than in the mother-cell fraction. Our results are consistent with the findings of an earlier genetic study indicating that spoIIID expression is required in the mother-cell but not in the forespore chamber of the sporangium (De Lencastre and Piggot 1979).

\section{Discussion}

Gene expression in the mother-cell chamber of the sporangium is controlled, in part, by a hierarchical regulatory cascade (for review, see Losick and Kroos 1989). spoIIID, the earliest acting regulatory gene so far identified in the cascade (Turner et al. 1986; Kunkel et al. 1988; L. Zheng and R. Losick, unpubl.|, governs the construction (by a chromosomal rearrangement) and transcription of the structural gene $\operatorname{sig} K$ for the mother-cell $\sigma$-factor $\sigma^{\mathrm{K}}$ (Kunkel et al. 1988; Kroos et al. 1989; Stragier et al. 1989|. $\sigma^{\mathrm{K}}$, in turn, switches on the transcription of gerE (Cutting et al. 1989; L. Kroos, unpubl.), a regulatory gene whose product governs gene expression at a late stage of development in the mother cell ( $\mathrm{L}$. Zheng and R. Losick, unpubl.). Our finding that spoIIID is preferentially expressed in the mother cell explains, at least in part, why the rearrangement (Stragier et al. 1989; B. Kunkel, R. Losick, and P. Stragier, unpubl.) and transcription (Kunkel et al. 1988) of sigK and, hence, subsequent gene expression (Cutting et al. 1989) in the cascade are compartmentalized. Also, our demonstration that expression of spoIIID commences at or shortly before the time at which the rearrangement occurs and at

Table 1. Effect of spo mutations on spoIIID-directed $\beta$-galactosidase synthesis

\begin{tabular}{|c|c|}
\hline Relevant mutation ${ }^{a}$ & Synthesis of $\beta$-galactosidase ${ }^{b}$ \\
\hline $\mathrm{spo}^{+}$ & 100 \\
\hline spoIIAC1 & $<5$ \\
\hline spoIID298 & 100 \\
\hline 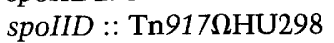 & 53 \\
\hline spoIIGB55 & $<5$ \\
\hline spoIIIA53 & 175 \\
\hline spoIIIA $::$ Tn $917 \Omega H U 25$ & 150 \\
\hline spoIIIC94 & 180 \\
\hline spoIIID 83 & 28 \\
\hline spoIIID $\Delta$ erm & 34 \\
\hline SpOIIIE36 & 54 \\
\hline spoIIIG $\Delta 1$ & 180 \\
\hline spoIVCA133 & 140 \\
\hline spoIVCB23 & 170 \\
\hline
\end{tabular}

a Strains bearing the mutations spoIIAC1 (1.5), spoIID298 (298.4), and spoIIGB55 (55.3) were isogenic to SG38. Strains bearing spoIID :: Tn917RHU298 (KS298), spoIIIA53 (SC615),

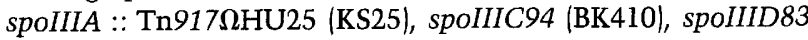
(BK395), spoIIIDAerm (BK541), spoIIIE36 (SC622), spoIIIGA1 (BK338), spoIVCA133 (BK558), and spoIVCB23 (BK556) were isogenic to PY79. An integrated copy of the spoIIID-lacZ fusion plasmid pBK45 was introduced into each strain as described in Methods.

b Expressed as a percentage of the level ( $\sim 45$ Miller units) of spoIIID-directed $\beta$-galactosidase synthesis observed in the corresponding isogenic wild-type $\left(\mathrm{Spo}^{+}\right)$strain at peak activity (6-8 hr\} after resuspension in SM medium. Background levels of $\beta$-galactosidase activity of the respective isogenic fusionless $\mathrm{Spo}^{+}$strain (1-3 Miller units) were subtracted. 


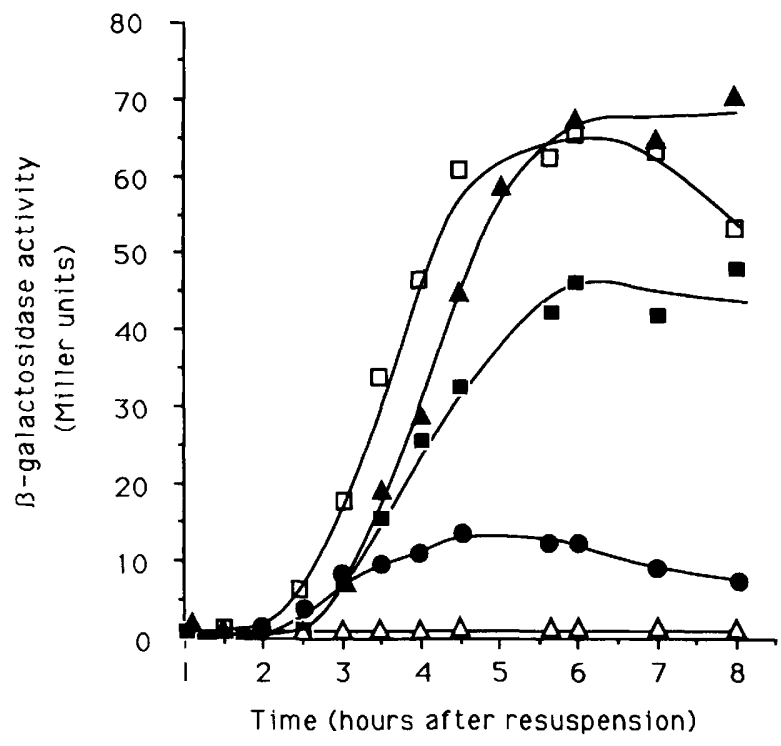

Figure 4. spoIIID-directed $\beta$-galactosidase synthesis in various spo mutants. The specific activity of $\beta$-galactosidase was determined at the indicated times after resuspension in SM medium of spo $^{+}$cells $(\square)$ or cells of mutant strains containing the following mutations: spoIIGB55 $(\triangle)$, spoIIID83 (U), spoIIIA:

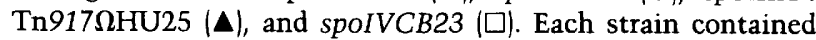
an integrated copy of the spoIIID-lacZ fusion-bearing plasmid pBK45 that had been introduced as described in Methods.

which the transcription of $\operatorname{sig} K$ (as monitored by the use of the spoIVCB-lacZ fusion; Fig. 3) is induced suggests that the activation of the regulatory cascade is directly attributable to the induction of spoIIID.

spoIIID encodes an activator of the sigK promoter

The spoIIID gene encodes a 93-residue-long polypeptide of $10.8 \mathrm{kD}$. The predicted amino acid sequence of this protein conforms exactly to the partial amino-terminal amino acid sequence of a previously identified transcription factor that binds to the promoter for $\operatorname{sigK}$ (R. Halberg and L. Kroos, unpubl.) and strongly stimulates its transcription (Kroos et al. 1989). Therefore, we assign spoIIID as the structural gene for this transcription factor and infer that the strong dependence of the induction of $\operatorname{sig} K$ transcription on the spoIIID gene product (Kunkel et al. 1988) is due to direct activation of the sigK promoter by SpoIIID protein. The presence of a region (residues 23-42 in Fig. 2) of striking similarity to the $\alpha$-helix $-\beta$-turn- $\alpha$-helix DNA-binding domain of many other prokaryotic transcriptional regulatory proteins (Pabo and Sauer 1984) is consistent with this view. Recently, spoIIID was cloned independently and sequenced by C. Stevens and J. Errington (pers. comm.), who confirm its assignment as the structural gene for the transcription factor of Kroos et al. (1989).

Role of the spoIIID gene product in the sigK chromosomal rearrangement

The discovery that the spoIIID gene product is a small, DNA-binding protein suggests two, nonmutually exclu- sive explanations for its requirement in the mother-cell chromosomal rearrangement. One possibility is that SpoIIID governs the transcription of the site-specific recombinase gene whose product catalyzes the juxtaposition of spoIVCB and spoIIIC sequences to create the composite sigK gene. Several lines of investigation (B. Kunkel, R. Losick, and P. Stragier, unpubl.) strongly suggest that the recombinase gene is spoIVCA, a sporulation gene that is located immediately adjacent to and in convergent orientation with spoIVCB /Fujita and Kobayashi 1985; Farquhar and Yudkin 1988; Kunkel et al. 1988; Stragier et al. 1989|. It will be of considerable interest to learn whether spoIVCA expression, like spoIVCB expression, depends on the spoIIID product. The other possibility is that SpoIIID is directly involved in the rearrangement process as part of a nucleosomelike, synaptic complex [purified SpoIIID is known to bind to the $\operatorname{spoIVCB}$ (i.e., $\operatorname{sigK}$ ) promoter region in vitro; R. Halberg and L. Kroos, unpubl.) that facilitates the recombination event. This would be analogous to the involvement of small host proteins in Salmonella phase variation and in excisive and integrative recombination by coliphage $\lambda$ (Better et al. 1983; Pollack and Nash 1983; Johnson et al. 1986; Thompson et al. 1987; Friedman 1988).

\section{Temporal and spatial regulation of spoIIID expression}

Finally, we consider the temporal and spatial regulation of spoIIID expression. Because spoIIID is at or near the top of the hierarchical regulatory cascade, the mechanisms that govern the timing and compartmentalization of its expression can be considered to be important determinants of the mother-cell line of gene expression.

Table 2. Compartmentalization of spoIIID expression

\begin{tabular}{lccc}
\hline Experiment & Mother-cell & Forespore & $\begin{array}{l}\text { Mother-cell/ } \\
\text { forespore } \\
\text { ratio }\end{array}$ \\
\hline 1 & 7.9 & 0.7 & 11.3 \\
2 & 12.8 & 2.2 & 5.8 \\
3 & 8.8 & 0.9 & 9.8 \\
\hline
\end{tabular}

Cells of strain PY79 containing an integrated copy of the spoIIID-lacZ fusion plasmid pBK45 were sporulated in DS medium (experiments 1 and 3 ) or in SM medium (experiment 2). Five-milliliter samples were collected at $T_{8}-T_{9}$ and fractionated into mother-cell and forespore fractions as described by Panzer et al. (1989). The specific activity of $\beta$-galactosidase in each fraction was determined and is expressed as nanomoles of ONPG hydrolyzed/min per milligram of protein. Specific activities from each of 3 independent experiments are shown. The data are averages of 4,2 , and 4 sets of measurements for experiments 1,2 , and 3 , respectively. The background specific activities of ONPG-hydrolyzing activity in the mother-cell $/ \sim 2$ $\mathrm{nmole} / \mathrm{min}$ per $\mathrm{mg}$ of protein) and forespore $(\sim 1.5 \mathrm{nmole} / \mathrm{min}$ per $\mathrm{mg}$ of protein) fractions from cells lacking the gene fusion were subtracted. For comparison the ratio of mother-cell 1270 $\mathrm{nmole} / \mathrm{min}$ per $\mathrm{mg}$ of protein) to forespore $(3200 \mathrm{nmole} / \mathrm{min}$ per $\mathrm{mg}$ of protein) specific activity for $s s p B$-directed $\beta$-galactosidase synthesis analyzed in parallel was 0.08 . 
We infer that spoIIID is under the control of the sporulation $\sigma$-factor $\sigma^{\mathrm{E}}$ (although biochemical experiments to determine if this control is direct have not yet been carried out) (1) because spoIIID expression commences shortly after the time that $\sigma^{\mathrm{E}}$ appears (Trempy et al. $1985 \mathrm{a}$ ), and (2) because spoIIID expression is completely dependent on spoIIGB, which encodes the pro- $\sigma$ precursor of $\sigma^{\mathrm{E}}$ (Stragier et al. 1984; Trempy et al. 1985a; Labell et al. 1987), and spoIIA, whose products are required for the processing of pro- $\sigma^{\mathrm{E}}$ to its mature and active form (Stragier et al. 1988). Therefore, we suggest that the time at which spoIIID is induced is determined principally by the time at which pro- $\sigma^{\mathbf{E}}$ processing occurs. [The time of spoIIID induction may not be determined exclusively by the appearance of mature $\sigma^{\mathrm{E}}$, however, because spoIIID induction occurs slightly later (see Results) than the time of induction of $\operatorname{spoIID,~a~}$ stage II gene whose transcription is known to be under the direct control of $\sigma^{\mathrm{E}}$ (Rong et al. 1986; Stragier et al. 1988).] It has been suggested that the conversion of pro$\sigma^{\mathrm{E}}$ to mature $\sigma^{\mathrm{E}}$ is coupled to the formation of the sporulation septum at morphological stage II of development (Labell et al. 1987; Stragier et al. 1988). If this hypothesis is correct, the dependence of pro- ${ }^{\mathrm{E}}$ processing on septum formation would ensure that spoIIID is not induced until after the sporangium has been partitioned into forespore and mother-cell compartments.

Although regulation by $\sigma^{\mathbf{E}}$ largely (if not entirely) explains the timing of spoIIID induction, transcription by $\sigma^{\mathrm{E}}$-RNA polymerase presumably cannot be the basis for the compartmentalization of spoIIID expression. Subcellular fractionation experiments show that $\sigma^{\mathrm{E}}$ is present in both compartments of the sporangium (Carlson and Haldenwang 1989), and dependence studies show that $\sigma^{\mathrm{E}}$ is required both for mother-cell and forespore gene expression (Errington and Mandelstam 1986b; Turner et al. 1986; Kunkel et al. 1988; Mason et al. 1988; Sandman et al. 1988; Karmazyn-Campelli et al. 1989). Therefore, we infer the existence of an additional regulatory mechanism superimposed on the recognition of the spoIIID promoter by $\sigma^{\mathrm{E}}$-RNA polymerase that limits spoIIID expression to the mother cell.

The nature of this compartmentalization mechanism is unknown, but our dependency studies suggest the possible existence of a positive feedback loop that could contribute to the differential expression of spoIIID in the mother cell. We interpret the observation that spoIIID expression is partially dependent on its own gene product, but not on the product of the downstream regulatory gene $\operatorname{sig} K$, to indicate that expression of spoIIID is stimulated by its own gene product; that is, that spoIIID expression is subject to autoregulation. Autoregulation could be expected to set up a positive feedback loop in which an underlying mother-cell bias in spoIIID expression (of unknown mechanistic basis) would preferentially stimulate further expression of spoIIID in the mother cell. This is analogous to the postulated role of autoregulation of the forespore $\sigma$-factor gene spoIIIG (sigG) and of the mother-cell $\sigma$-factor gene sigK in enhancing compartmentalized synthesis of $\sigma^{\mathrm{G}}$ and $\sigma^{\mathrm{K}}$, respectively (Karmazyn-Campelli 1989; Kroos et al. 1989). A possible additional feature of such a positive feedback loop that would reinforce the differential expression of spoIIID in the mother cell is suggested by the observation that the spoIIID gene product oligomerizes (Kroos et al. 1989; L.Kroos and R. Losick, unpubl.). If the active form of the spoIIID gene product in autoregulation is an oligomer, then positive regulation of spoIIID by SpoIIID protein would be highly sensitive to the spoIIID protein concentration and, hence, would occur much more efficiently in the mother cell than in the forespore, assuming an underlying mother-cell bias in spoIIID expression.

\section{Methods}

\section{Bacterial strains}

B. subtilis strains KS25 (spoIIIA :: Tn917RHU25; Sandman et al. 1987), KS298 (spoIID :: Tn917RHU298; Sandman et al. 1987), SC615 (spoIIIA53; Cutting et al. 1989), SC622 (spoIIIE36; Cutting et al. 1989), BK338 (spoIIIGA1; Kunkel et al. 1988), BK395 (spoIIID83; Kunkel et al. 1988), BK410 (spoIIIC94; Kunkel et al. 1988), BK556 (spoIVCB23; this work), BK558 (spoIVCA133; this work), and BK541 (spoIIIDAerm; this work, see below) were isogenic with strain PY79. Strains BK556 and BK558 were constructed by PBS1-mediated transduction of BK407 (aroD120; Kunkel et al. 1988) to prototrophy using PBS1 lysates grown on strain 23.1 (spoIVCB23 trpC2; J. Errington, Oxford University) and $1 S 47$ (spoIVCA133 trpC2; Bacillus Genetic Stock Center), respectively, taking advantage of the linkage of spoIVCA and spoIVCB $(50 \%)$ to aroD120. Strains 1.5 (spoIIAC1 trpC2), 298.4 (spoIID298 trpC2) and 55.3 (spoIIGB trpC2) were isogenic with strain SG38 and were provided by J. Errington (Errington and Mandelstam 1986a).

\section{Cloning of spoIIID}

The spoIIID gene was cloned in $B$. subtilis by selection for complementation of mutation spoIIID83 by use of the prophage transformation system of Poth and Youngman (1988). A library of SP $\beta$-transducing phages containing Sau3A-generated, partially digested fragments of $B$. subtilis DNA in the size range of 5-8 kb was used to infect spolIID 83 mutant cells. Lysogens were selected by resistance to chloramphenicol. After growth under sporulation conditions, $\mathrm{Spo}^{+}$lysogens were selected by resistance to chloroform. A lysate was prepared by thermoinduction of the $\mathrm{Spo}^{+}$lysogens and used, once again, to infect spoIIID83 mutant cells. One such transducing phage (HP64) that was capable of complementing the spoIIID 83 mutation contained an insert of $\sim 6 \mathrm{~kb}$. To rescue the spoIIID gene from the phage, we took advantage of the presence of a derivative of the $E$. coli plasmid vector $\mathrm{pBR} 322$ in the SP $\beta$ phage at a location adjacent to the BamHI site into which chromosomal DNA had been inserted and the presence of a unique EcoRI site in the insert distal to the pBR322 replicon. Phage DNA was cut with EcoRI and circularized by ligation at low DNA concentration and used to transform competent $E$. coli cells to ampicillin resistance.

\section{Generation of nested deletions}

A series of nested deletions of the spoIIID gene used for sequencing and subcloning was generated by the method of Dale et al. (1985). A fragment of $B$. subtilis DNA of $\sim 4 \mathrm{~kb}$, extending 
from the left end of the $\mathrm{p} \beta \mathrm{E}-68$ insert (i.e., the $\mathrm{BamHI} / \mathrm{Sau} 3 \mathrm{~A}$ junction of insert and vector DNA) to the SstI site indicated in Figure 1 was subcloned into phage M13mp19. Single-stranded DNA was isolated from the recombinant phage and used to create nested deletions whose end points are indicated in Figure 1.

\section{Construction of plasmid subclones}

Plasmid pBK32 was constructed by inserting the 4-kb BamHISstI fragment that had been gel-purified from p $\beta E-68$ DNA into the polylinker of pIBI30 (International Biotechnologies). Plasmids pCK1, pCK3, pCK5, and pCK7 were constructed by gel-purifying the indicated restriction fragments from pBK32 and cloning them into the polylinker of pSGMU2 (Fort and Errington 1985). Deletion subclones pCK9, pBK34, pBK39, pBK41, and $\mathrm{pBK} 42$ were constructed by transferring the indicated fragments from phage M13mp19 bearing the indicated deletions into pUC18. The inserts were gel-purified from replicative form (double-stranded) phage DNA that had been digested with EcoRI, which cuts in the M13mp19 polylinker at a site adjacent to the deletion end point, and with the indicated restriction enzyme (BamHI, HindIII, or DraI).

\section{Nucleotide sequencing}

The spoIIID gene was sequenced across both strands by the dideoxy chain termination method of Sanger et al. (1977). The 3' strand of the gene was sequenced by using the universal M13 sequencing primer and phage M13mp19 DNA bearing the $\Delta 21$ and $\Delta 3$ deletion-mutated DNAs (Figs. 1 and 2) as templates. The 5' strand of the gene was sequenced by using as templates single-stranded phage M13mp18 DNA into which the $1.5-\mathrm{kb}$ HindIII-PstI insert of pCK5 had been cloned (Fig. 1). The following synthetic oligonucleotides were used as primers for sequencing the 5' strand 5'-GATGAATGAGGTGTCTG-3' (centered at 375 bp upstream of the spoIIID ORF), 5'-CCTAACAAAGAGAGTGT-3' (centered at 150 bp upstream of the ORF), and 5'-CAGTACACAAGGATTTA-3' 'centered at codon 39 within the ORF (Fig. 2)].

\section{Construction of mutant cells bearing a spoIIID deletion mutation}

The deletion mutation spoIIID $\Delta$ erm was constructed in vitro by replacing the interval between the RsaI site at codon 15 and the Rsal site at codon 37 with an erythromycin-resistance cassette of $\sim 1 \mathrm{~kb}$. A 500-bp RsaI-RsaI fragment containing the 5' region of spoIIID and extending to the RsaI site at codon 15 (Fig. 2) was cloned into the polylinker of pUC18 at the HincII site in the orientation such that the spoIIID ORF read toward the $E c o R I$ site in the polylinker. The resulting plasmid, $\mathrm{pCK} 13$, was linearized with KpnI and BamHI (which cut uniquely in the polylinker at sites adjacent to the RsaI site at codon 15), and a gel-purified 1-kb KpnI-BamHI fragment carrying the erm cassette isolated from pUC18erm (Kenney and Moran 1987) was inserted to create $\mathrm{pBK} 43$. A 360 -bp RsaI-EcoRI fragment isolated from $\mathrm{pBK} 39$, extending from the RsaI site at codon 37 to the deletion end point $\Delta 21$ (Fig. 1), was gel-purified and inserted into pBK43 that had been linearized at the ClaI site (located in the polylinker adjacent to the end of the erm casette distal to the 5 ' end of the spoIIID ORFI, treated with Klenow enzyme to generate blunt ends, and then digested with EcoRI. The resulting plasmid, pBK46, contained the $5^{\prime}$ and $3^{\prime}$ portions of the spoIIID ORF in the same orientation, as was verified by endonuclease restriction analysis. pBK46 was linearized with HindIII, which cuts outside of spoIIID $\Delta$ erm, and was used to transform competent cells of strain PY79 to erythromycin resistance (25 $\mu \mathrm{g} / \mathrm{ml}$ lincomycin, $1 \mu \mathrm{g} / \mathrm{ml}$ erythromcyin) to generate the spoIIID $\Delta e r m$, deletion-mutated strain BK541. That the wildtype spoIIID gene in the chromosome had been substituted by marker replacement (double) recombination with mutant DNA in strain BK541 was verified by Southern hybridization analysis.

Insertion of spolIID at the amy locus

A fragment of $\sim 500$ bp that extended from an XmnI site located $\sim 230$ bp upstream of the first codon of the spoIIID ORF to an XmnI site located 30 bp downstream of the end of the ORF was gel-purified from pBK39 (Fig. 1) and subcloned into pUC1 8 that had been linearized with $S m a I$ to generate plasmid pBK49. The 500-bp insert containing the spoIIID gene was then released from pBK49 by digestion with EcoRI and HindIII and inserted into pDG268 (Karmazyn-Campelli et al. 1989), a derivative of the amy-integration vector of Shimotsu and Henner (1986) that had been linearized with both EcoRI and HindIII. The resulting plasmid, pBK51, was linearized with XhoI and used to transform competent wild-type cells of strain PY79 tr chloramphenicol resistance. The resulting transformants were screened for those exhibiting an Amy ${ }^{-}$phenotype (Shimotsu and Henner 1986). Chromosomal DNA from one chloramphenicol-resistant Amy- transformant (BK607) was purified and used to introduce the wild-type spoIIID gene into spoIIID83 and spoIIIDSerm mutant cells by transformation.

\section{Construction of spoIIID-lacZ fusion}

The spoIIID-lacZ fusion was created by joining the lacZ gene of $E$. coli in-frame to the first codon of the spoIIID ORF. pBK39 (see Fig. 1 and above) was linearized with ApaLI, partially filled in with Klenow enzyme in the presence of only dTTP and dGTP, and then mildly digested with mung bean nuclease (New England Biolabs) to generate blunt-ended fragments. Then the DNA was digested with HindIII and the 730-bp HindIIIApaLI (blunt) fragment containing the $5^{\prime}$ portion of the gene and extending into the ORF to include only the first codon of spoIIID was gel-purified and inserted into the lac $Z$-cat vector pSGMU37 (Errington 1986) that had been digested with Xhol, filled in with Klenow enzyme, and digested with HindIII. The resulting plasmid, pBK45, contained an in-frame fusion of spoIIID-lacZ, as was verified by DNA sequencing across the junction of spoIIID and lac $Z$ sequences.

\section{Introduction of spoIIID-lacZ gene fusion into the chromosome}

The spoIIID-lacZ fusion was inserted into the chromosome by single-reciprocal (Campbell-like) recombination at the spoIIID locus by transformation of competent cells of the strain PY79 with plasmid pBK45 (see above) and selection for chloramphenicol resistance. To introduce the spoIIID-lacZ fusion into other wild-type and mutant strains, chromosomal DNA was purified from one chloramphenicol-resistant transformant (BK533) and used to transform competent cells of the indicated strains to chloramphenicol resistance.

\section{Transformation of B. subtilis}

Competent cells were prepared and transformed as described by Dubnau and Davidoff-Abelson (1971).

\section{Growth and sporulation}

Growth and sporulation in Difco sporulation (DS) medium were carried out as described by Sandman et al. (1988). Induc- 
tion of sporulation induced by resuspension in SM medium was carried out by the method of Sterlini and Mandelstam (1969). Samples to be analyzed for $\beta$-galactosidase activity were collected at the indicated times after the end of exponential growth and stored frozen at $-70^{\circ} \mathrm{C}$.

\section{Measurement of $\beta$-galactosidase activity}

The specific activity of $\beta$-galactosidase was determined as described by Miller (1972) with the substrate 0 -nitrophenol- $\beta$-Dgalactoside (ONPG). One unit of enzyme hydrolyzes $1 \mu$ mole ONPG/min per $\mathrm{A}_{595}$ unit. The background activity of ONPGhydrolyzing activity $(\sim 2$ Miller units $)$ in cells of the $\mathrm{Spo}^{+} \mathrm{pa}-$ rental strains PY79 and SG38 lacking the gene fusion was subtracted from the values obtained for cells containing the spoIIID-lacZ fusions.

\section{Acknowledgments}

We thank S. Cutting, L. Zheng, A. Grossman, A.L. Sonenshein, and $\mathrm{P}$. Stragier for helpful discussions and advice on the manuscript. We also thank A.L. Sonenshein for help with the analysis of the spoIIID sequence and C. Kroeger for technical assistance. B.K. was a predoctoral fellow of the National Science Foundation, and L.K. was a postdoctoral fellow of the Helen Hay Whitney Foundation. This work was supported by National Instutites of Health grants GM-18568 to R.L. and GM-35495 to P.Y.

\section{Note added in proof}

Sequence data described in this paper have been submitted to the EMBL/GenBank Data Libraries under accession number $\mathrm{X} 15520$.

\section{References}

Aronson, A.I. and P.C. Fitz-James. 1976. Structure and morphogenesis of the bacterial spore coat. Bacteriol. Rev. 40: 360402.

Better, M., S. Wickner, I. Auerbach, and H. Echols. 1983. Role of the Xis protein of bacteriophage $\lambda$ in a specific reactive complex at the attR prophage attachment site. Cell 32: $161-168$.

Carlson, H.C. and W.G. Haldenwang. 1989. The $\sigma^{\mathrm{E}}$ subunit of Bacillus subtilis RNA polymerase is present in both forespore and mother cell compartments. I. Bacteriol. 171: 2216-2218.

Cutting, S., S. Panzer, and R. Losick. 1989. Regulatory studies on the promoter for a gene governing synthesis and assembly of the spore coat in Bacillus subtilis. I. Mol. Biol. 207: 393-404.

Dale, R.M.K., B.A. McClure, and J.P. Houchins. 1985. A rapid single-stranded cloning strategy for producing a sequential series of overlapping clones for use in DNA sequencing: Application to sequencing the corn mitochondrial $18 \mathrm{~S}$ rDNA. Plasmid 13: 31-40.

De Lencastre, H. and P.J. Piggot. 1979. Identification of different sites of expression for spo loci by transformation of Bacillus subtilis. J. Gen. Microbiol. 114: 377-389.

Donovan, W.P., L. Zheng, K. Sandman, and R. Losick. 1987. Genes encoding spore coat polypeptides from Bacillus subtilis. I. Mol. Biol. 196: 1-10.

Dubnau, D. and R. Davidoff-Abelson. 1971. Fate of transforming DNA following uptake by competent Bacillus sub- tilis. I. Formation and properties of the donor-recipient complex. J. Mol. Biol. 56: 209-221.

Errington, J. 1986. A general method for fusion of the Escherichia coli lacZ gene to chromosomal genes in Bacillus subtilis. J. Gen. Microbiol. 132: 2953-2966.

Errington, J. and J. Mandelstam. 1986a. Use of a lacZ gene fusion to determine the dependence pattern of sporulation operon spoIIA in spo mutants of Bacillus subtilis. J. Gen. Microbiol. 132: 2967-2976.

- 1986b. Use of a lacZ gene fusion to determine the dependence pattern and the spore compartment expression of sporulation operon spoVA in spo mutants of Bacillus subtilis. J. Gen. Microbiol. 132: 2977-2985.

Farquhar, R. and M.D. Yudkin. 1988. Phenotypic and genetic characterization of mutations in the spoIVC locus of $B a$ cillus subtilis. J. Gen. Microbiol. 134: 9-17.

Fort, P. and J. Errington. 1985. Nucleotide sequence and complementation analysis of a polycistronic sporulation operon, spoVA, in Bacillus subtilis. I. Gen. Microbiol. 131: 10911105.

Francesconi, S.C., T.J. MacAlister, B. Setlow, and P. Setlow. 1988. Immunoelectron microscopic localization of small, acid-soluble spore proteins in sporulating cells of Bacillus subtilis. J. Bacteriol. 170: 5963-5967.

Friedman, D. 1988. Integration host factor: A protein for all reasons. Cell 55: 545-554.

Fujita, M. and Y. Kobayashi. 1985. Cloning of sporulation gene spoIVC in Bacillus subtilis. Mol. Gen. Genet. 199: 471-475.

Jenkinson, H. F., W. D. Sawyer, and J. Mandelstam. 1981. Synthesis and order of assembly of spore coat proteins in $\mathrm{Ba}$ cillus subtilis. J. Gen. Microbiol. 123: 1-16.

Johnson, R.C., M.F. Bruist, and M.I. Simon. 1986. Host protein requirements for in vitro site-specific DNA inversion. Cell 46: $531-539$.

Karmazyn-Campelli, C., C. Bonamy, B. Savelli, and P. Stragier. 1989. Tandem genes encoding $\sigma$-factors for consecutive steps of development in Bacillus subtilis. Genes Dev. 3: $150-157$.

Kenney, T.J. and C.P. Moran. 1987. Organization and regulation of an operon that encodes a sporulation-essential sigma factor in Bacillus subtilis. J. Bacteriol. 169: 3329-3339.

Kroos, L., B. Kunkel, and R. Losick. 1989. Switch protein alters specificity of RNA polymerase containing a compartment specific sigma facor. Science 243: 526-529.

Kunkel, B., K. Sandman, S. Panzer, P. Youngman, and R. Losick. 1988. The promoter for a sporulation gene in the spoIVC locus of Bacillus subtilis and its use in studies of temporal and spatial control of gene expression. I. Bacteriol. 170: $3513-3522$.

Labell, T.L., J.E. Trempy, and W.G. Haldenwang. 1987. Sporulation specific $\sigma$ factor $\sigma^{29}$ of Bacillus subtilis is synthesized from a precursor protein, $\mathbf{P}^{31}$. Proc. Natl. Acad. Sci. 84: $1784-1788$.

Losick, R. and L. Kroos. 1989. Dependence pathways for the expression of genes involved in endospore formation in $\mathrm{Ba}$ cillus subtilis. In Regulation of procaryotic development. (ed. I. Smith, R. Slepecky, and P. Setlow), pp. 223-241. American Society for Microbiology, Washington, D.C.

Losick, R. and P. Youngman. 1984. Endospore formation in Bacillus. In Microbial development. (ed. R. Losick, and L. Shapiro), pp.63-88. Cold Spring Harbor Labortory, Cold Spring Harbor, New York.

Losick, R., P. Youngman, and P.J. Piggot. 1986. Genetics of endospore formation in Bacillus subtilis. Annu. Rev. Genet. 20: 625-669.

Mason, J.M., R.H. Hackett, and P. Setlow. 1988. Studies on the regulation of expression of genes coding for small, acid-sol- 
Kunkel et al.

uble proteins of Bacillus subtilis spores using lacZ gene fusions. J. Bacteriol. 170: 239-244.

Miller, J.H. 1972. In Experiments in molecular genetics. Cold Spring Harbor Laboratory, Cold Spring Harbor, New York.

Pabo, C.O. and R.T. Sauer. 1984. Protein-DNA recognition. Annu. Rev. Biochem. 53: 293-321.

Panzer, S., R. Losick, D. Sun, and P. Setlow. 1989. Evidence for an additional temporal class of gene expression in the forespore compartment of sporulating Bacillus subtilis. J. Bacteriol. 171: $561-564$.

Piggot. P.J. and J.G. Coote. 1976. Genetic aspects of bacterial endospore formation. Bacteriol. Reviews. 40: 908-962.

Pollack, T. J. and H. A. Nash. 1983. Knotting of DNA caused by a genetic rearrangement: Evidence for a nucleosome-like structure in site-specific recombination of bacteriophage lambda. J. Mol. Biol. 170: 1-18.

Poth, H. and P. Youngman. 1988. A new cloning system for Bacillus subtilis comprising elements of phage, plasmid and transposon vectors. Gene 73: $215-226$.

Rong, S., M.S. Rosenkrantz, and A.L. Sonenshein. 1986. Transcriptional control of the Bacillus subtilis spollD gene. $J$. Bacteriol. 165: 771-779.

Sandman, K., R. Losick, and P. Youngman. 1987. Genetic analysis of spo mutations generated by $\mathrm{Tn} 917$-mediated insertional mutagenesis. Genetics 117: 603-617.

Sandman, K., L. Kroos, S. Cutting, P. Youngman, and R. Losick. 1988. Identification of the promoter for a spore coat protein gene in Bacillus subtilis and studies on the regulation of its induction at a late stage of sporulation. I. Mol. Biol. 200: $461-473$.

Sanger, F., S. Nicklen, and A.R. Coulson. 1977. DNA sequencing with chain terminating inhibitors. Proc. Natl. Acad. Sci. 74: 5463-5467.

Setlow, P. 1988. Small, acid-soluble spore proteins of Bacillus species: Structure, synthesis, genetics, function, and degradation. Annu. Rev. Microbiol. 42: 319-338.

Shimotsu, H. and D.J. Henner. 1986. Construction of a singlecopy integration vector and its use in analysis of regulation of the trp operon of Bacillus subtilis. Gene 43: 85-94.

Sterlini, J.M. and J. Mandelstam. 1969. Commitment to sporulation in Bacillus subtilis and its relationship to the development of actinomycin resistance. Biochem. I. 113: 29-37.

Stragier, P., C. Bonamy, and C. Karmazyn-Campelli. 1988. Processing of a sporulation sigma factor in Bacillus subtilis: How morphological structure could control gene expression. Cell 52: 697-704.

Stragier, P., J. Bouvier, C. Bonamy, and J. Szulmajster. 1984. A developmental gene product of Bacillus subtilis homologous to the sigma factor of Escherichia coli. Nature 312: 376-378.

Stragier, P., B. Kunkel, L. Kroos, and R. Losick. 1989. Chromosomal rearrangement generating a composite gene for a developmental transcription factor. Science 243: 507-512.

Sun, D., P. Stragier, and P. Setlow. 1989. Identification of a new $\boldsymbol{\sigma}$-factor involved in compartmentalized gene expression during sporulation of Bacillus subtilis. Genes Dev. 3: 141149.

Thompson, J.F., L. Moitoso de Vargas, S.E. Skinner, and A. Landy. 1987. Protein-protein interactions in a higher-order structure direct lambda site-specific recombination. J. Mol. Biol. 195: 481-493.

Trempy, J.E., J. Morrison-Plummer, and W.G. Haldenwang. 1985b. Synthesis of $\sigma^{29}$, an RNA polymerase specificity determinant, is a developmentally regulated event in Bacillus subtilis. J. Bacteriol. 161: 340-346.

Trempy, J.E., C. Bonamy, J. Szulmajster, and W.G. Haldenwang. 1985b. Bacillus subtilis sigma factor $\sigma^{29}$ is the product of the sporulation-specific gene spoIIG. Proc. Natl. Acad. Sci. 82: 4189-4192.

Turner, S.M., J. Errington, and J. Mandelstam. 1986. Use of a lacZ gene fusion to determine the dependence pattern of sporulation operon spoIIIC in spo mutants of Bacillus sub tilis: A branched pathway of expression of sporulation operons. J. Gen. Microbiol. 132: 2995-3003. 


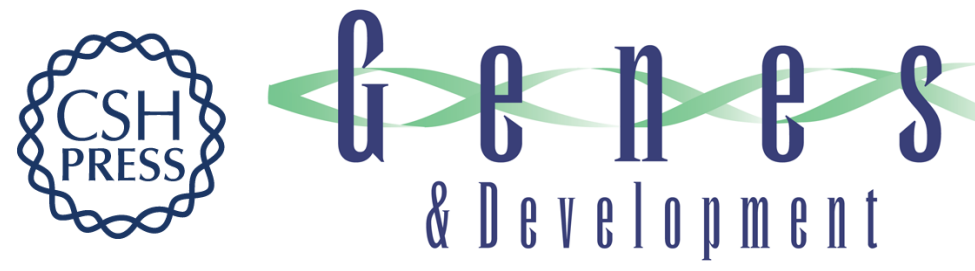

\section{Temporal and spatial control of the mother-cell regulatory gene spolild of Bacillus subtilis.}

B Kunkel, L Kroos, H Poth, et al.

Genes Dev. 1989, 3:

Access the most recent version at doi:10.1101/gad.3.11.1735

References This article cites 45 articles, 18 of which can be accessed free at:

http://genesdev.cshlp.org/content/3/11/1735.full.html\#ref-list-1

License

Email Alerting

Service

Receive free email alerts when new articles cite this article - sign up in the box at the top right corner of the article or click here.

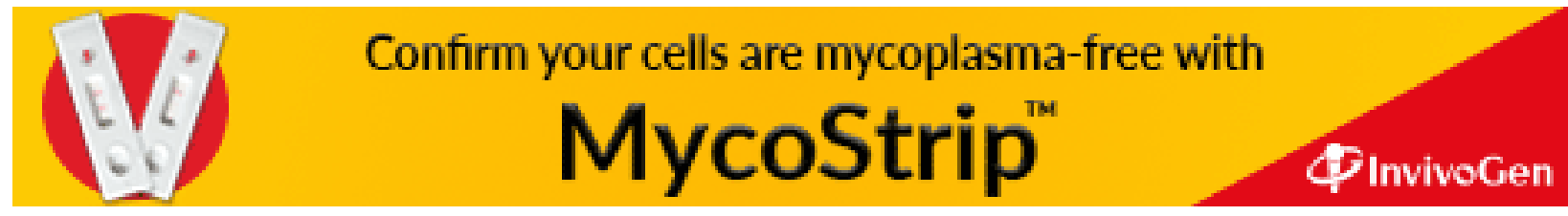

